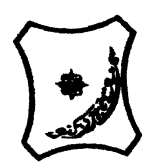

Bayero Journal of Pure and Applied Sciences, 12(1): 70 - 80

Received: October, 2018

Accepted: May, 2019

ISSN $2006-6996$

\title{
MATHEMATICAL MODELING OF THE TRANSMISSION DYNAMICS, CONTROL AND VACCINATION OF SCHISTOSOMIASIS WITH A VARIABLE POPULATION SIZE
}

\author{
Musa, $\mathbf{S}^{\mathbf{1}}$., Bello, $\mathbf{N}^{2}$. and Umar, $\mathbf{A}^{\mathbf{3}}$. \\ ${ }^{1,3}$ Department of Mathematics, Modibbo Adama University of Technology, P.M.B 2076,Yola - \\ Nigeria \\ ${ }^{1}$ samdurkwa@yahoo.com, ${ }^{2}$ nafisatbello@gmail.com, ${ }^{3}$ ahmedumar42@gmail.com \\ *E-mail Corresponding author:samdurkwa@yahoo.com, Tel: 234-7037266718, 08182672728
}

\section{ABSTRACT}

In this paper, a compartmental mathematical model for the transmission dynamics of schistosomiasis in human, cattle and snail populations with a variable population size; and vaccination as a control strategy has been studied. The basic reproduction number $R_{0}$ of the model has been computed. Disease free- equilibrium state and its local stability using next generation matrix and linearization method were used respectively; the model was found out to be locally asymptotically stable (LAS) given that $R_{0}<1$. The numerical results revealed that, high rate of vaccination use decreases both susceptible and infected populations in both human and cattle. It is therefore sufficient to adhere to the vaccination exercise on both susceptible and infected human and cattle populations to exterminate schistosomiasis.

Keywords: schistosomiasis, Vaccination; variable population; Stability; strategy

\section{INTRODUCTION}

One of the most serious public health problems in the tropics and subtropics is human schistosomiasis (Bilharziasis), a parasitic infection caused by flatworms of the family Schistosoma that live in fresh water habitats. Schistosomiasis is characterized by long-term disability and is estimated to affect over 200 million people mostly in underdeveloped countries where the disease is endemic. According to the survey done in 2003 by World Health Organization (WHO), more than 200 million people are infected and over 600 million people in 74 countries are at risk of the infection. Mortality rate exceeds 100,000 annually and schistosomiasis remains formidable to humans because of the complexities of parasitic adjustment to two or more different hosts (Garrett, 1994; McNeill, 1977).

The persistence of schistosomiasis infection in a locality depends on a complex cycle involving humans and possibly additional mammalian species called definite hosts, such includes some particular species of snails and certain parasitic flatworms (schistosomes). Schistosomes are digenetic trematodes that spend their adult life in humans and a previous stage in aquatic snails (Jordan et al., 1993). Anderson and May (1992) confirmed that Schistosomes live inside blood vessels; the adult schistosome worms mate heterosexually, laying hundreds of eggs and these eggs are deposited in intestine or bladder; eventually passed out as faeces or urine in fresh water bodies. In the fresh water bodies, snail asexually produces cercariae, at maturity human comes with contact with the cercariae and subsequently pairing with the opposite sex, copulation and oviposition which begins the cycle over again

The transmission of schistosomiasis is associated with water development projects such as dams for irrigation systems and fish-farming, as the snail intermediate hosts of the parasites breed in them and human water contact (Klump and Webbe, 1987; WHO, 1989; WHO, (1993)). Schistosomiasis, being a water-based disease is spread through contact with water in which snails harbouring and shedding the infective stage (cercariae) of the parasite (schistosome) are present (Costa et al., 1993).

Schistosomiasis has been classified as a neglected tropical disease (NTD), although an estimated 779 million people in the world are at risk of the infection according to recent surveys (Steinmann et al., 2006; Hotez et al., 2007). 
BAJOPAS Volume 12 Number 1, June, 2019

Human schistosomiasis is caused by five species of flatworms: Schistosoma mansoni, Schistosoma intercalatum, Schistosoma japonicum, Schistosoma mekongi, and Schistosoma haematobium. Three of these species ( $S$. mansoni, $S$. haematobium and $S$. intercalatum) are endemic in Nigeria, which led to the formation of a national schistosomiasis control program in the late 1980s. Estimates in the mid-1990s suggested that more than 100 million people were at risk of this disease and that 25.8 million people were actually infected (Chitsulo et al., 2000). More recently the latter figure was updated to 29 million infections (Steinmann et al., 2006; Moné et al., 2010), which corresponds to $14 \%$ of the global number of schistosomainfections and puts Nigeria at the top of the list of endemic countries.

One of the control strategy of schistosomiasis is vaccination, and vaccines that would specifically reduce parasite reproduction and egg viability may also be a desirable goal. Silvera et al., 2004 confirmed that, an alternative vaccinology approach, is inducing immunity with attenuated parasites has provided the strongest animal proof-of-concept that vaccines against schistosomiasis are feasible.

Enormous research has been going on to device control strategies to deal with the menace, more importantly transmission dynamics of schistosomiasis via mathematical model that brought substantial insight on the control strategies. Since 1973, there have been many mathematical models of the transmission dynamics of schistosomes examples are works done by Anderson and May (1985, 1992); Kimbir (1997); Wu and Feng (2002); Feng et al., (2001); Riley et al. (2008); Mangal et al., (2008); Zimin et al. (2010) and among others.

Zimin et al. (2010) proposed a mathematical model for the human-cattle-snail transmission of schistosomiasis in Hubei Province of China. The compartmental model consists of human, cattle and snail populations and each populations entails susceptible and infected compartments. The results suggested that, to control or eradicate schistosomiasis in the studied region, a more comprehensive approach is needed to consider environmental factors in order to break the cattle-snail transmission.

The aim of this paper is to modify the model due to Zimin et al. (2010) by incooperating vaccination as a control strategy and considered a variable population size. Also, Death due to natural death is accounted for in the model considering the fact that death due to natural death can occur in both susceptible and infected humans, cattle, and snails

\subsection{MATERIALS AND METHODS}

Table 1: Modified Model State Variable and their Description

\begin{tabular}{ll}
\hline Variable & Description \\
\hline$V_{H}(t)$ & Vacinated compartment for human $t$ \\
$V_{C}(t)$ & Vacinated compartment for cattle $t$ \\
$S_{H}(t)$ & Susceptible human population at time $\mathrm{t}$ \\
$S_{S}(t)$ & Susceptible snail population at time $\mathrm{t}$ \\
$S_{C}(t)$ & Susceptible cattle population at time $\mathrm{t}$ \\
$I_{H}(t)$ & Infected human population at time $\mathrm{t}$ \\
$I_{S}(t)$ & Infected snail population at time $\mathrm{t}$ \\
$I_{C}(t)$ & Infected cattle population at time $\mathrm{t}$ \\
\hline
\end{tabular}


BAJOPAS Volume 12 Number 1, June, 2019

Table 2: Modified Model Parameters and their Description

\begin{tabular}{|c|c|}
\hline Parameters & Descriptions \\
\hline$b_{H}$ & Natural birth rate of human \\
\hline$\beta_{S H}$ & transmisson rate from infected snail to human \\
\hline$r_{H}$ & recovery rate of infectes human \\
\hline$b_{C}$ & natural birth rate of cattle \\
\hline$\beta_{S C}$ & transmisson rate from infected snail to cattle \\
\hline$d_{C}$ & death rate of infected snails \\
\hline$\underline{\left(b_{C}-d_{C}\right)}$ & carrying capacity of cattle \\
\hline$k_{C}$ & \\
\hline$r_{C}$ & recovery rate of infectes cattle \\
\hline$b_{S}$ & natural birth rate of snails \\
\hline$\beta_{H S}$ & transmisson rate from infected human to snail \\
\hline$\beta_{C S}$ & transmisson rate from infected cattle to snail \\
\hline$d_{S}$ & transmisson rate from infected cattle to snails \\
\hline$\underline{\left(b_{S}-d_{S}\right)}$ & carrying capacity of snails \\
\hline$k_{S}$ & \\
\hline$d_{H}$ & Death due to the disease in human \\
\hline$\mu_{H}$ & Death due to natural causes in human \\
\hline$\mu_{S}$ & Death due to natural causes in Snail \\
\hline$\mu_{C}$ & Death due to natural causes in cattle \\
\hline$v_{H}$ & Vaccination rate for human \\
\hline$\varepsilon_{H}$ & Rate of loss of immunity in human \\
\hline$v_{C}$ & Vaccination rate for Cattle \\
\hline$\varepsilon_{C}$ & Rate of loss of immunity in cattle \\
\hline
\end{tabular}

\section{$2.1 \quad$ Zimin et al. (2010) Assumptions}

Zimin et al. (2010) made the following assumptions that:

i. Human, cattle and snail populations are all positive, i.e $N_{H}>0, S_{C}+I_{C}>0$ and $S_{S}+I_{S}>0$.

ii. The birth rate is greater than the death rate for both cattle and snails, i.e., $b_{c}-d_{c}>0$ and $b_{s}-d_{s}>0$.

2.2 Zimin et al. (2010) Model Equations

$$
\begin{aligned}
& \frac{d S_{H}}{d t}=\beta_{S H} S_{H} I_{S}+r_{H} I_{H} \\
& \frac{d I_{H}}{d t}=\beta_{S H} S_{H} I_{S}-r_{H} I_{H} \\
& \frac{d S_{C}}{d t}=b_{C}\left(S_{C}+I_{C}\right)-\beta_{S C} S_{C} I_{S}+r_{C} I_{C}-d_{C} S_{C}-k_{C} S_{C}\left(S_{C}+I_{C}\right)+I_{C} \\
& \frac{d I_{C}}{d t}=\beta_{S C} S_{C} I_{S}-r_{C} I_{C}-d_{C} I_{C}-k_{C} I_{C}\left(S_{C}+I_{C}\right)_{C} \\
& \frac{d S_{S}}{d t}=b_{S}\left(S_{S}+I_{S}\right)-\beta_{H S} S_{S} I_{H}-\beta_{C S} S_{S} I_{C}-d_{S} S_{S}-k_{S} S_{S}\left(S_{S}+I_{S}\right) \\
& \frac{d I_{S}}{d t}=\beta_{H S} S_{S} I_{H}+\beta_{C S} S_{S} I_{C}-d_{S} I_{S}-k_{S} I_{S}\left(S_{S}+I_{S}\right)
\end{aligned}
$$


BAJOPAS Volume 12 Number 1, June, 2019

2.3 Modified Model Assumptions

iii. Human, cattle and snail populations are all positive, i.e $N_{H}>0, S_{C}+I_{C}>0$ and $S_{S}+I_{S}>0$.

iv. The birth rate is greater than the death rate for both cattle and snails, i.e., $b_{c}-d_{c}>0$ and $b_{s}-d_{s}>0$.

v. $\quad$ The recruitment rate of human into the susceptible class by natural birth.

vi. The vaccinated chambers as vaccines availability for both human and cattle are feasible.

vii. Death due to natural death can occur in both susceptible and infected humans, cattle, and snails

\subsection{Modified Model Equations}

$$
\begin{aligned}
\frac{d S_{H}}{d t} & =b_{H} N_{H}-\beta_{S H} S_{H} I_{S}+r_{H} I_{H}-v_{H} S_{H}+\varepsilon_{H} V_{H}-\mu_{H} S_{H} \\
\frac{d I_{H}}{d t} & =\beta_{S H} S_{H} I_{S}-\left(d_{H}-\mu_{H}\right) I_{H}-r_{H} I_{H} \\
\frac{d S_{C}}{d t} & =b_{C} N_{C}-\beta_{S C} S_{C} I_{S}+r_{C} I_{C}-\mu_{C} S_{C}-k_{C} S_{C}\left(S_{C}+I_{C}\right)-\mu_{C} S_{C}+\varepsilon_{C} V \\
\frac{d I_{C}}{d t} & =\beta_{S C} S_{C} I_{S}-r_{C} I_{C}-\left(d_{C}+\mu_{C}\right) I_{C}-k_{C} I_{C}\left(S_{C}+I_{C}\right)_{C} \\
\frac{d S_{S}}{d t} & =b_{S} N_{S}-\beta_{H S} S_{S} I_{H}-\beta_{C S} S_{S} I_{C}-\mu_{S} S_{S}-k_{S} S_{S}\left(S_{S}+I_{S}\right) \\
\frac{d I_{S}}{d t} & =\beta_{H S} S_{S} I_{H}+\beta_{C S} S_{S} I_{C}-\left(d_{S}+\mu_{S}\right) I_{C}-k_{S} I_{S}\left(S_{S}+I_{S}\right) \\
\frac{d V_{H}}{d t} & =v_{H} S_{H}-\varepsilon_{H} v_{H}-\mu_{H} V_{H} \\
\frac{d V_{C}}{d t} & =v_{C} S_{C}-\varepsilon_{C} v_{C}-\mu_{C} V_{C}
\end{aligned}
$$

Therefore equations (1)-(8) are transform into proportions, and hence our reduced model equations are given below:

$$
\begin{aligned}
& i_{h}^{\prime}=B_{S H}\left(1-v_{h}\right)-\left(B_{S H}+r_{H}+d_{H}+b_{H}-d_{H} i_{h}\right) i_{h} \\
& v_{h}^{\prime}=v_{H}\left(1-i_{h}\right)-\left(v_{H}+\varepsilon_{H}+b_{H}-d_{H} i_{h}\right) v_{h} \\
& i_{c}^{\prime}=B_{S C}\left(1-v_{c}\right)-\left(B_{S C}+r_{C}+d_{C}+b_{C}-d_{C} i_{c}\right) i_{c} \\
& v_{c}^{\prime}=v_{C}\left(1-i_{c}\right)-\left(v_{C}+\varepsilon_{C}+b_{C}-d_{C} i_{c}\right) v_{c} \\
& i_{S}^{\prime}=B_{H S}+B_{C S}-\left(B_{H S}+B_{C S}+d_{S}+b_{S}-d_{S} i_{S}\right) i_{s}
\end{aligned}
$$

\subsection{RESULTS}

\subsection{Disease Free Equilibrium (DFE) State of the Model}

To obtain the disease free equilibrium (DFE) of the model, set the right hand side of equations (9)(13) to zero, and letting $i_{h}=i_{c}=i_{S}=0$ at disease free equilibrium. Resolving the equations yield the followings:

$$
v_{h}=\frac{v_{H}}{v_{H}+\varepsilon_{H}+b_{H}} \text {, and } v_{c}=\frac{v_{C}}{v_{C}+\varepsilon_{C}+b_{C}}
$$

Remember that the following equations hold throughout this study

$$
B_{S H}=\beta_{S H} I_{S}, B_{S C}=\beta_{S C} I_{S}, B_{C S}=\beta_{C S} I_{S}, B_{H S}=\beta_{H S} I_{H}
$$

Hence, the disease free equilibrium point is given as:

$$
\left(i_{h}, v_{h}, i_{c}, v_{c}, i_{s}\right)=\left(0, \frac{v_{H}}{v_{H}+\varepsilon_{H}+b_{H}}, 0, \frac{v_{C}}{v_{C}+\varepsilon_{C}+b_{C}}, 0\right)
$$


BAJOPAS Volume 12 Number 1, June, 2019

\subsection{Basic Reproduction Number of the Model}

The basic reproduction number denoted by $R_{0}$ could be computed by using next-generation matrix. This method is given by Driessche and Watmough, (2002). Therefore, get $F$ and $V$ as given below:

$$
\begin{aligned}
F & =\left[\begin{array}{l}
\beta_{S H} I_{S} \\
\beta_{S C} I_{S} \\
\beta_{H S} I_{H}+\beta_{C S} I_{C}
\end{array}\right] \\
V & =\left[\begin{array}{l}
\left(B_{S H} V_{h}-\left(B_{S H}+r_{H}+d_{H}+b_{H}-d_{H} i_{h}\right) i_{h}\right) \\
\left(B_{S C} V_{C}-\left(B_{S C}+r_{c}+d_{c}+b_{c}-d_{c} i_{c}\right) i_{c}\right) \\
\left(B_{H S}+B_{C S}+d_{s}+b_{s}-d_{s} i_{s}\right) i_{s}
\end{array}\right]
\end{aligned}
$$

So, taking partial derivatives of equations (16) - (17) and evaluated at disease free equilibrium state gives the followings:

$$
F=\left[\begin{array}{ccc}
0 & 0 & \beta_{S H} \\
0 & 0 & \beta_{S C} \\
\beta_{H S} & \beta_{C S} & 0
\end{array}\right], \quad V=\left[\begin{array}{ccc}
r_{H}+d_{H}+b_{H} & 0 & 0 \\
0 & r_{C}+d_{C}+b_{C} & 0 \\
0 & 0 & d_{S}+b_{S}
\end{array}\right]
$$

Solving $F V^{-1}$ of the two equations in (18) with the largest eigen value is given below:

$$
R_{0}=\sqrt{\frac{\left(r_{H}+d_{H}+b_{H}\right) \beta_{C S}^{2}+\beta_{H S}^{2}\left(r_{C}+d_{C}+b_{C}\right)}{\left(r_{H}+d_{H}+b_{H}\right)\left(r_{C}+d_{C}+b_{C}\right)\left(d_{S}+b_{S}\right)}}
$$

\subsection{Local stability of the disease free equilibrium (DFE) State}

Linearization approach is used to examine the local stability of the disease free equilibrium (DFE) state, this is done by obtaining the Jacobian matrix of the model equations in proportion given by (9) to (13). Thus, the Jacobian evaluated at disease free equilibrium is given below:

$$
J=\left[\begin{array}{ccccc}
-\left(B_{H S}+r_{H}+d_{H}+b_{H}\right) & -B_{H S} & 0 & 0 & 0 \\
-v_{H}+\frac{d_{H}\left(B_{S H}+v_{H}\right)}{B_{H S}+v_{H}+\varepsilon_{H}+b_{H}} & -\left(v_{H}+\varepsilon_{H}+b_{H}\right) & 0 & 0 & 0 \\
0 & 0 & -\left(B_{C S}+r_{C}+d_{C}+b_{C}\right) & -B_{C S} & 0 \\
0 & 0 & -v_{C}+\frac{d_{C}\left(B_{C S}+v_{C}\right)}{B_{C S}+v_{C}+\varepsilon_{C}+b_{C}} & -\left(v_{C}+\varepsilon_{C}+b_{C}\right) & 0 \\
0 & 0 & 0 & 0 & -\left(B_{H S}+B_{C S}+d_{S}+b_{S}\right)
\end{array}\right]
$$

For simplification purpose, let's denote

$$
\begin{aligned}
& q=\left(B_{H S}+r_{H}+d_{H}+b_{H}\right), \quad p=v_{H}+\frac{d_{H}\left(B_{S H}+v_{H}\right)}{B_{H S}+v_{H}+\varepsilon_{H}+b_{H}}, \quad \omega=\left(v_{H}+\varepsilon_{H}+b_{H}\right), \quad k=\left(B_{C S}+r_{C}+d_{C}+b_{C}\right) \\
& \text {, } P=v_{C}+\frac{d_{C}\left(B_{C S}+v_{C}\right)}{B_{C S}+v_{C}+\varepsilon_{C}+b_{C}}, \quad l=\left(v_{C}+\varepsilon_{C}+b_{C}\right), \quad n=\left(B_{H S}+B_{C S}+d_{S}+b_{S}\right) \text {, } \\
& f=v_{C}+\frac{d_{C}\left(B_{C S}+v_{C}\right)}{B_{C S}+v_{C}+\varepsilon_{C}+b_{C}}
\end{aligned}
$$

Therefore equation (20) becomes

$$
|J-\lambda I|=\left|\begin{array}{ccccc}
-q-\lambda & -B_{H S} & 0 & 0 & 0 \\
P & -\omega-\lambda & 0 & 0 & 0 \\
0 & 0 & -k-\lambda & -B_{C S} & 0 \\
0 & 0 & f & -l-\lambda & 0 \\
0 & 0 & 0 & 0 & -n-\lambda
\end{array}\right|=0
$$

Solving equation (21) for eigene values gives the followings: 
BAJOPAS Volume 12 Number 1, June, 2019

$$
\begin{aligned}
& \lambda_{4}, \lambda_{5}=\frac{-(k+l) \pm \sqrt{(k+l)^{2}-4\left(B_{C S} f+l k\right)}}{2} \\
& \lambda_{4}=\frac{-(k+l)+\sqrt{(k+l)^{2}-4\left(B_{C S} f+l k\right)}}{2} \\
& \lambda_{5}=\frac{-(k+l)-\sqrt{(k+l)^{2}-4\left(B_{C S} f+l k\right)}}{2}
\end{aligned}
$$

Therefore, the disease free equilibrium state is stable if and only if $B_{H S}\left(v_{C}+\frac{d_{C}\left(B_{C S}+v_{C}\right)}{B_{C S}+v_{C}+\varepsilon_{C}+b_{C}}\right)<\left(v_{H}+\varepsilon_{H}+b_{H}\right)$.

4.0 Simulation Results

In this section, graphical solutions in Figure 1 to 10 are presented to show the effects of vaccination and variable population on the transmission dynamics of schistosomiasis. The parameters values used

\begin{tabular}{|c|c|c|}
\hline Parameters/Variables & Values & Referrences \\
\hline$\overline{V_{H}(0)}$ & 15 & Assumed \\
\hline$V_{C}(0)$ & 30 & Assumed \\
\hline$S_{H}(0)$ & 90 & Assumed \\
\hline$S_{S}(0)$ & 100 & Assumed \\
\hline$S_{C}(0)$ & 200 & Assumed \\
\hline$I_{H}(0)$ & 20 & Assumed \\
\hline$I_{S}(0)$ & 30 & Assumed \\
\hline$I_{C}(0)$ & 50 & Assumed \\
\hline$\beta_{S H}$ & $2.23 \times 10^{-7}$ & Allen and Victory, (2003) \\
\hline$r_{H}$ & $4.47 \times 10^{-7}$ & Allen and Victory, (2003) \\
\hline$b_{C}$ & $1.20 \times 10^{-3}$ & Allen and Victory, (2003) \\
\hline$\beta_{S C}$ & $2.00 \times 10^{-3}$ & Allen and Victory, (2003) \\
\hline$d_{C}$ & $5.00 \times 10^{-6}$ & Allen and Victory, (2003) \\
\hline$\left(b_{C}-d_{C}\right)$ & $7.00 \times 10^{-3}$ & Allen and Victory, (2003) \\
\hline \multicolumn{3}{|l|}{$k_{C}$} \\
\hline$r_{C}$ & $2.4 \times 10^{-2}$ & Allen and Victory, (2003) \\
\hline$b_{S}$ & $6.00 \times 10^{-2}$ & Allen and Victory, (2003) \\
\hline$\beta_{H S}$ & $1.04 \times 10^{-5}$ & Allen and Victory, (2003) \\
\hline$\beta_{C S}$ & $1.05 \times 10^{-7}$ & Allen and Victory, (2003) \\
\hline$d_{S}$ & $8.86 \times 10^{-3}$ & Allen and Victory, (2003) \\
\hline$\frac{\left(b_{S}-d_{S}\right)}{k_{S}}$ & $7.00 \times 10^{-3}$ & Allen and Victory, (2003) \\
\hline
\end{tabular}
in the simulations are presented in Table 3

Table 3:values for state variables and Parameters 


$\begin{array}{lll}\text { Table } 3 \text { Continue } & 0.312 & \text { Kbenesh et al. (2009) } \\ b_{H} & 4.0 \times 10^{-5} & \text { Hyun (2001) } \\ \mu_{H} & 5.0 \times 10^{-4} & \text { WHO (2003) } \\ d_{H} & 8.86 \times 10^{-3} & \text { Allen and Victory, (2003) } \\ \mu_{S} & 5.00 \times 10^{-3} & \text { Allen and Victory, (2003) } \\ \mu_{C} & 0.00-0.75 & \text { Assumed } \\ v_{H} & 0.31 & \text { Assumed } \\ \varepsilon_{H} & 0.00-0.75 & \text { Assumed } \\ v_{C} & 0.23 & \text { Assumed } \\ \varepsilon_{C} & & \end{array}$

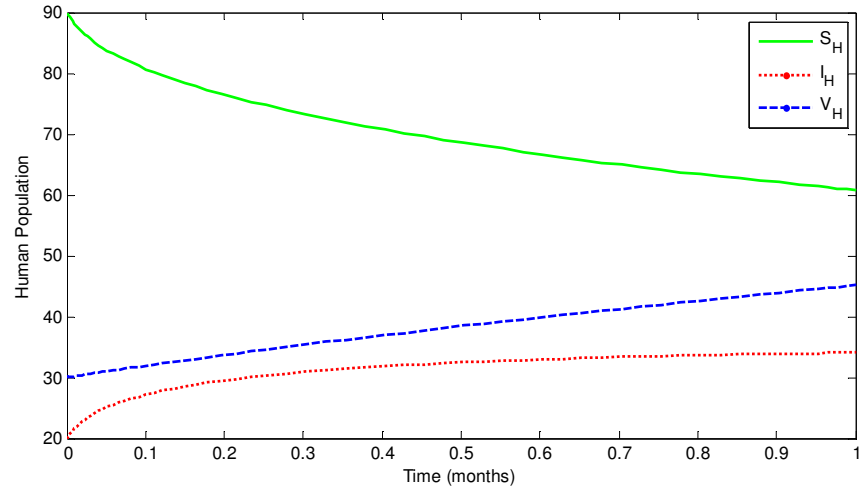

Figure 1: Human population with vaccination and variable population size

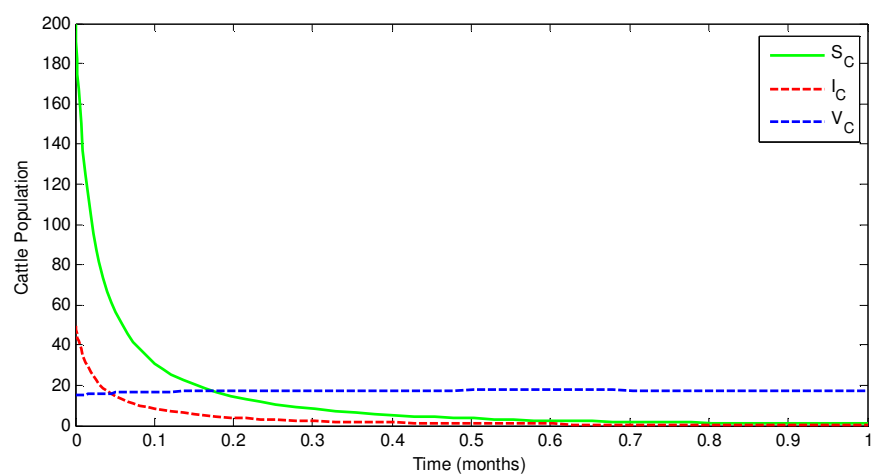

Figure 2: Cattle population with vaccination and variable population size

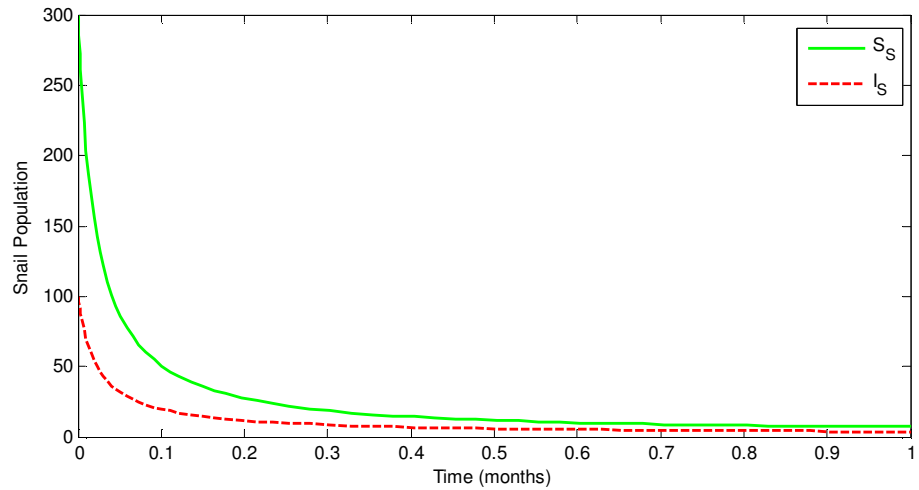

Figure 3: Snail population for the model with variable population size 
BAJOPAS Volume 12 Number 1, June, 2019

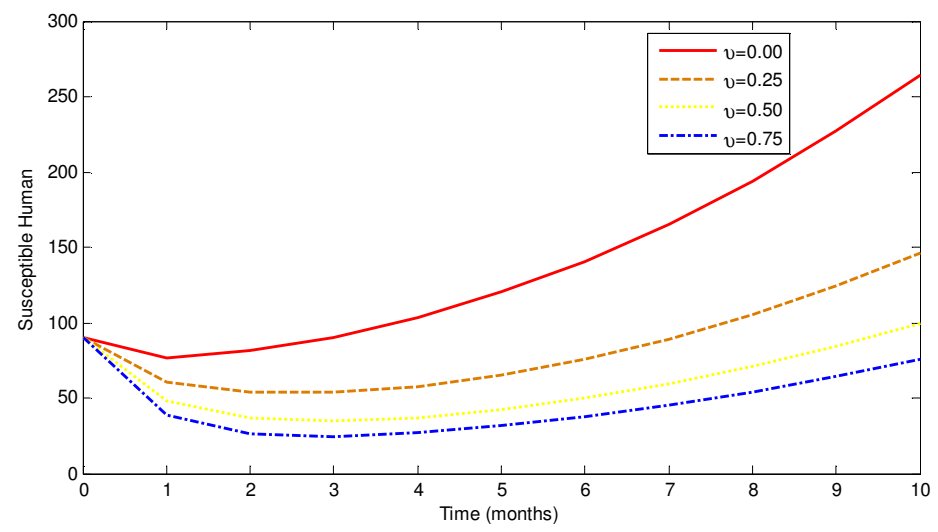

Figure 4: Effects of vaccination rate on susceptible human

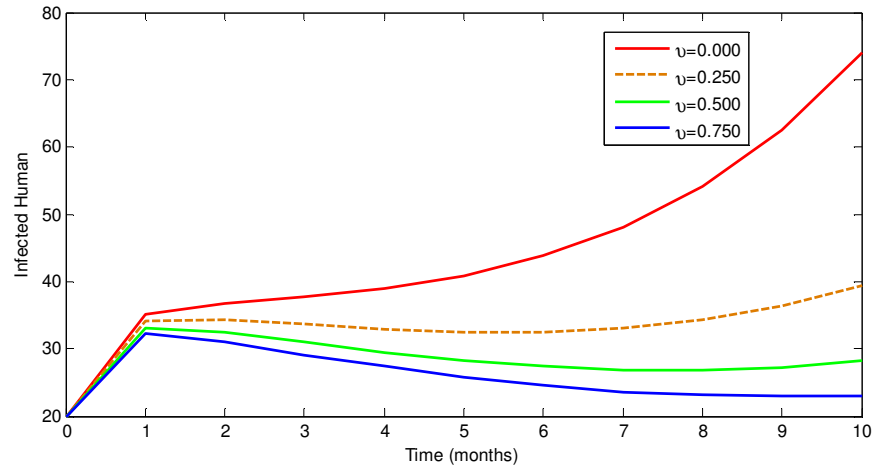

Figure 5: Effects of vaccination rate on infected human

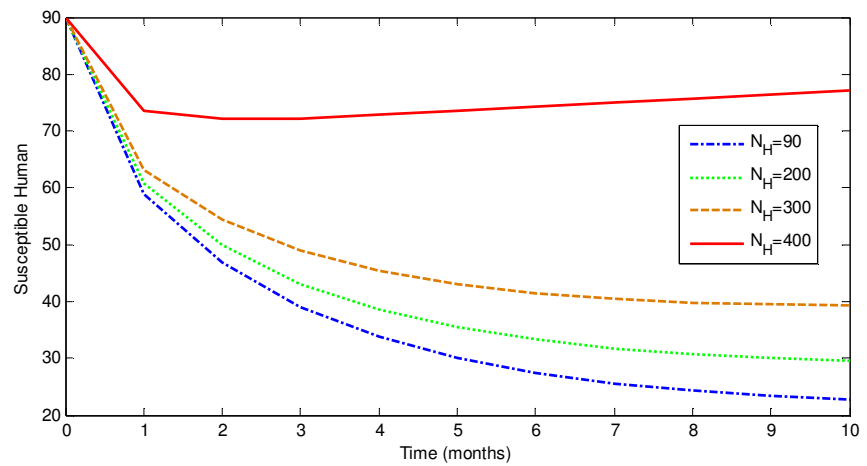

Figure 6: Effects of variable human population on susceptible human

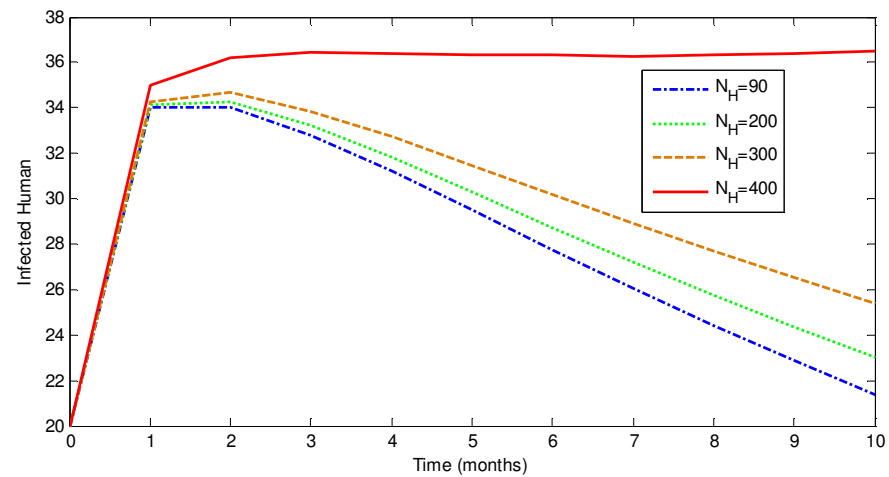

Figure 7: Effects of variable human population on infected human 
BAJOPAS Volume 12 Number 1, June, 2019

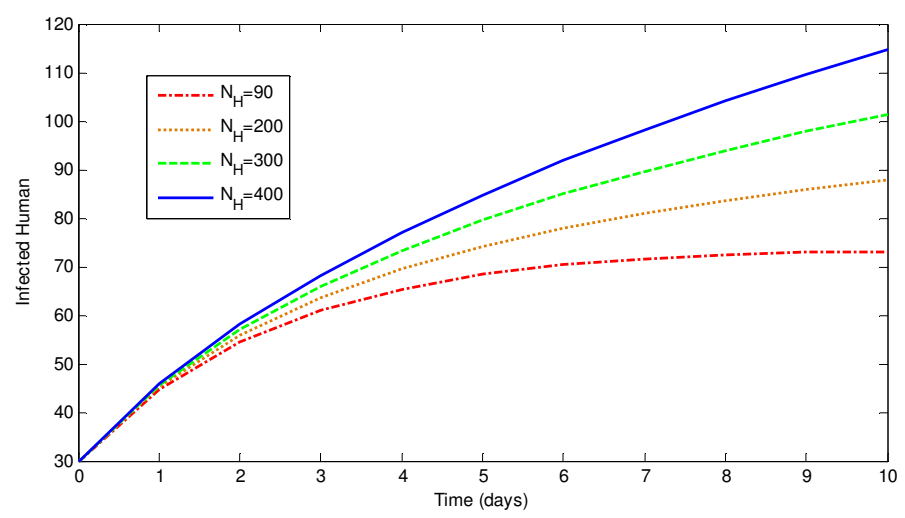

Figure 8: Effects of variable human population on infected human

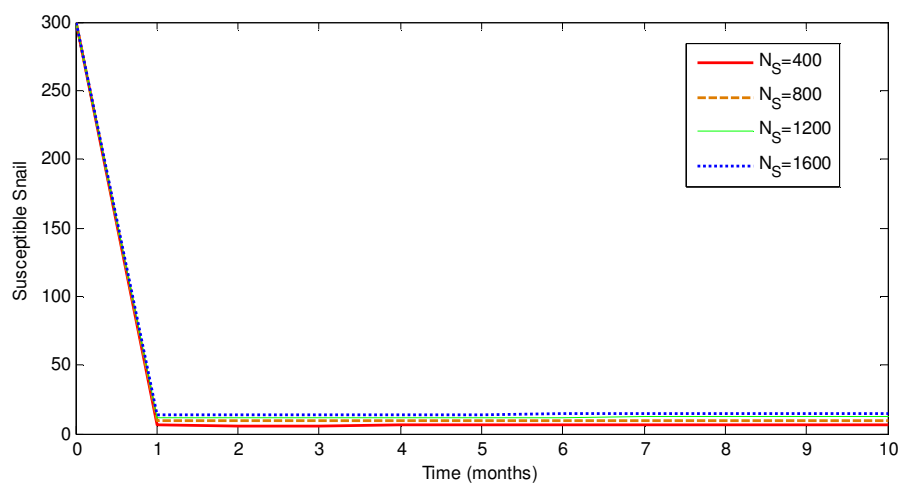

Figure 9: Effects of variable snail population on susceptible snail

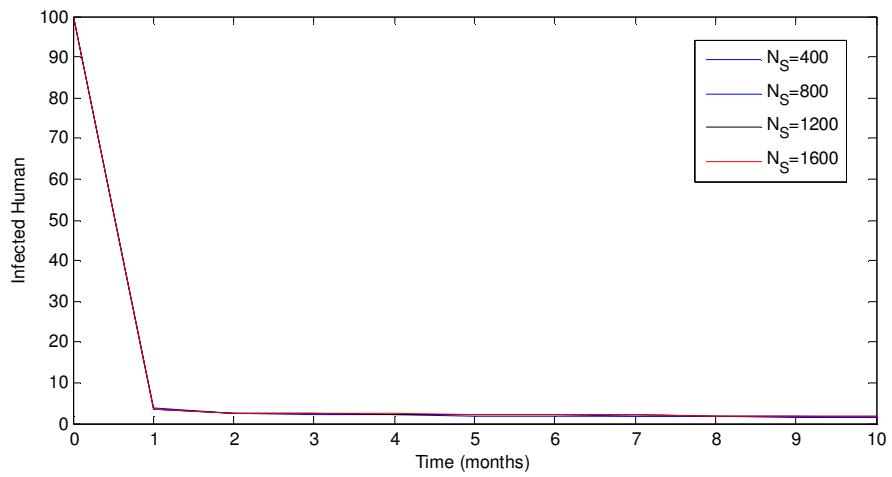

Figure 10: Effects of variable snail population on infected snail

\subsection{DISCUSSION OF RESULTS}

In this experiment, it is observed that in Figure 1 both infected human and vaccinated human populations gradually increase over time while susceptible humans' population dropped sharply as time goes on. Moreover, in figure 2 both susceptible and infected populations of cattle decrease whereas vaccinated population increases over time. In another experiment in figure 3, both susceptible and infected snail populations decrease over time.

Figure 4 shows the effect of vaccination on susceptible human, it is observed that as vaccination rate increases from 0.00 to 0.75 , susceptible human population decreases. Similarly, figure 5 shows the effect of vaccination on infected human, it is observed that as vaccination rate increases at $0.00,0.25$, 0.50 , and 0.75 there was a corresponding decrease in the infected human population over time.

The effect of variable human populations on susceptible and infected human, show that as the total population of human increases; both susceptible human and infected human correspondingly increase; see figure 6 and figure 7 respectively. 
BAJOPAS Volume 12 Number 1, June, 2019

On the contrary, figure 8 shows that, as the variable human population increases, vaccinated human population decrease steadily. Meanwhile, variable snail population on both susceptible and infected snails has no effect whatsoever as depicted in figure 9 and figure 10

\subsection{CONCLUSION}

The results in this paper agree with previous works showing the importance of the use of vaccine in checking the spread of schistosomiasis in human, cattle and snail populations. In such work, high rate of vaccination use decreases both susceptible and infected population in human, cattle and snail. In addition, results in this study revealed that,

\section{REFERENCES}

Allen, E. J \& Victory, H. D (2003). Modelling and Simulation of a Schistosomiasis Infection with Biological Control. Acta Trop, 87(2): 251-67.

Anderson, R. M. \& May, R. M. (1985). Helminthic Infections of Humans: Mathematical Models, Population Dynamics, and Control. Advanced Parasitology, 24: 1101

Anderson, R.M. \&May, R.M., (1992). Infectious Diseases of Humans: Dynamics and Control. Oxford University Press, Oxford.

Costa de Limae, M.F.F., Pocha, R.S. Filhocoura, P. \& Katz, N. (1993). A 13 Years Followup of Treatment and Snail Control in the Endemic Area for Schistosoma mansoni in Brazil, Incidence of Infection and Reinfection. Bulletin ofWorld Health Organisation.71(2): 197 - 205.

Chitsulo. L., Engels, D., Montresor, A. \& Savioli L. (2000). The global status of schistosomiasis and its control. Acta Tropica 77, 41-51.

Feng, Z., Curtis, J. \& Minchella, D.J. (2001). The influence of drug treatment on the maintenance of schistosome genetic diversity. Journal of Mathematical Biology. 43 (1): 52- 68.

Garrett, L.(1994). The Coming Plague: Newly Emerging Diseases in a World Out of Balance. Penguin Books, New York.

Hotez, P. J., Molyneux, D. H., Fenwick, A., Kumaresan, J., Ehrlich, S., Sachs, J. D., Savioli L, (2007). Control of neglected tropical diseases. N Engl J Me., 357: 1018-1027

Jordan, P. Webbe, G, Sturrock R. (1993): Human schistosomiasis. Wallingford, England: $C A B$,

Kimbir, A.R., (1997). A mathematical model of the transmission dynamics of variable human populations on both susceptible and infected human has positive effect while it has negative effect on vaccinated human population. Conversely, effect of variable snail population on both susceptible and infected snails remain trivial. Hence, to pull stop to the menace of schistosomiasis, vaccination is an essential control strategy.

\section{Contributions of the authors}

Musa, S. and Bello, N. jointly formulated the model equations and carried out the stability analysis, while Umar, A. performed the numerical experiments using MATLAB R2016a.

\section{Conflict of Interests}

The authors declare that there is no conflict of interests.

schistosomiasis. Journal of Nigerian Mathematical Society, 16 (17): 39-63

Klump, R. K. \& Webbe, G. (1987). Focal Seasonal and Behavioural Patterns of Infection and Transmission of $S$. haematobium in a Farming Village of the Volta Lake, Ghana. Journal of Tropical Medicine and Hygiene, 90:265281.

Mangal TD, Paterson S, Fenton A (2008) Predicting the Impact of Long-Term Temperature Changes on the Epidemiology and Control of Schistosomiasis: A Mechanistic Model. Plos one 3(1): 143-156

McNeill, W., H. (1977). Plagues and Peoples. Doubleday, New York.

Moné, H., Ibikounlé, M., Massougbodji, A.\&Mouahid, G. (2010). Human schistosomiasis in theeconomic community of West African states: epidemiology and control. Adv Parasitol 71:33-91.

Riley S., Carabin, H., Bélisle, P., Joseph, I., Tallo, V., Balolong, E., Willingham, A.L., Fernandez, T.J., Gonzales, R.N., Olveda, R. \& McGarvey, S.T. (2008). Multi-HostTransmission Dynamics of Schistosoma japonicum in Samar Province. Plos one 10:1371-1382

Steinmann, P., Keiser, J., Bos, R., Tanner, M., and Utzinger J. (2006). Schistosomiasis and water resources development: systematic review, meta-analysis, and estimates of people at risk. Lancet 12:12-21

Silveira, A.M., et al., (2004) Human schistosomiasis mansoni: intensity of infection differentially affects the production of interleukin-10, interferongamma and interleukin-13 by soluble egg antigen or adult worm antigen 
BAJOPAS Volume 12 Number 1, June, 2019

stimulated cultures. Trans R Soc Trop Med HygW.H.O. Status of Vaccine Research and Development of Vaccines for Schistosomiasis. 98(9): p514-9

W.H.O. (1989). Report on Tropical Diseases. TDR 9th Programme Report.

W.H.O. (2003). Status of Vaccine Research and Development of Vaccines for Schistosomiasis

World Health Organization, (1993). The control of schistosomiasis. Second Report of the WHO Expert Committee. WHO Technical Report Series No. 830.

Wu, J., Feng, Z., (2002). Mathematical models for schistosomiasis with delays and multiple definite hosts. In: CastilloChavez, C., Blower, S., van der Driessche, P., Kirchner, D., D., Yakubu, A.-A. (Eds.), Mathematical Approaches for Emerging and Re-emerging Infectious Diseases: Models, Methods, and Theory. Springer, New York, pp. 215229.

Zimin, C., Lan, Z., Dingwen, S., Weinian, Z. \& Shigui, R. (2010).Mathematical modelling and control of Schistosomiasis in Hubei Province, China. Acta Tropica, 11(5) 9- 17 